\title{
The Internet, The Cloud, and Information Technology Governance
}

\author{
Mehdi Asgarkhani ${ }^{1, *}$, Christopher Bartlett ${ }^{2}$, Dave Bracken ${ }^{3}$ \\ 1,2,3 Ara Institute of Canterbury, New Zealand \\ ${ }^{1}$ mehdi.asgarkhani@ara.ac.nz* \\ * corresponding author
}

(Received July 1, 2019 Revised October 21, 2019 Accepted October 29, 2019, Available online October 29, 2019)

\begin{abstract}
Information Technology Governance (ITG) has become a catalyst for strategic evaluation and deployment of IT solutions. Much of the concepts, the mechanisms, the processes, the frameworks, and the standards of ITG date back to the 1990s. A review of recent studies indicates an increased uptake of ITG practices within organizations - mostly via the adoption of ITG standards and frameworks. Within the last decade, we have witnessed rapid technological advancements which have in turn motivated radical changes in the management of IT infrastructure, deployment of IT applications, and delivery of IT services. For instance, Data Centers and Cloud Services have transformed the paradigm of infrastructure and application management in the IT sector. Moreover, sophisticated smart mobile solutions have made it possible to develop IoT solutions enabling smart cities and smart building initiatives. A review of timelines when ITG concepts and standards established suggest that they originated years before recent transformations in technology adoption took place. Some ITG standards show that the adoption of some cloud services motivated revision in some ITG frameworks. This study demonstrates that there is a possibility that some of the current ITG standards are not fine-tuned to reflect recent developments in the adoption of IT solutions and services.
\end{abstract}

Keywords: IT Governance; Cloud Computing; Cloud Services; IoT; IT Governance Frameworks;

\section{Introduction}

The competitive imperative of the private sector has driven business into the digital world. Many organizations around the world consider information technology (IT) as essential for establishing competitive businesses, managing global companies, adding business value and providing valuable products and services to their potential markets [12].

As capital investment in IT continues to grow, there is hope that IT managers and strategists are optimistic about investing in technology. More specifically, they need to maximize profits and at the same time minimize the risks that can be associated with technological change. As a result, the company places significant value on making decisions about both the direction (strategy) and the implementation of IT. In general, a portfolio of practices that guides strategy assessment, setting direction, and deciding IT tools is often referred to as Information Technology Governance (ITG).

ITG involves strategic and operational elements. A strategy analysis framework is one of the key tools in assessing best practice and direction for IT use in an organization. At the same time, there are various ITG standards and frameworks being developed to facilitate the tactical and operational aspects of IT.

Effective ITG depends not only on a clear and accurate understanding of the organization's current position, but also its future goals. What's more, ITG tools, standards and frameworks must be relevant and aligned with current trends in IT adoption. Effectiveness is a broad term. IT researchers and strategists have different views about effectiveness. For example, Hagen [4] outlines seven organizational habits that can result in effective ITG; as follows:

- Organizations view IT as a strategic business asset. IT assets are managed as a portfolio.

- Ignorance of technology is not an accepted culture. IT managers participate in technology investment decisions.

- IT has oversight at board level. There is clear executive leadership.

- The 'one size fits all' model for governance is not accepted.

- IT is an essential component of corporate planning and strategy. 
- IT managers take an active leadership role in transformation and innovation.

- The impact of IT on business is measured and monitored.

This paper discusses the broad likelihood of current ITG practices being relevant and effective: The approach taken to determine the likely effectiveness is as follows:

- Examine the timeframe in which key ITG concepts and philosophies were established.

- Investigate the time when ITG standards and frameworks were introduced.

- Review developments in the IT sector including technology and management practices.

- Examine whether ITG tools and concepts have been adapted to reflect changes in technology adoption.

The purpose of this investigation is to establish a preliminary understanding of the impact of cloud technologies and cloud services on the broad governance practices for managing IT. More specifically, to assess the extent of change in current IT Governance frameworks to reflect the recent developments as related to cloud services.

This pilot study is not intended at discussing technology details as related to infrastructure, applications, and other technology-related aspects of the cloud. The focus is on governance practices that must ensure best practice and achievement of desired outcomes of cloud adoption.

The methodology for this study mainly involves a review of previous research and technical documentation on standards and frameworks of IT Governance. The approach to analysis is to establish firstly current practices of IT Governance and associated frameworks. Next, to look at commonalities related to current IT Governance standards and the management of cloud solutions. Finally, establish if current governance standards have been modified to incorporate cloud services related governance factors into existing standards.

\section{An Overview of ITG}

IT Governance is a subset of the discipline that is referred to as Corporate Governance - it is focused on information and ICT assets. ICT governance was initially driven by compliance issues (such as Sarbanes-Oxley in the USA and Basel II in Europe). However, IT governance practices today require the close engagement of management at a higher level. What's more, the board of directors in organizations must make sure that management teams are not only aware of information resources available but also conditions of use and the role they play in making more effective decisions and generating a higher level of income [17].

IT Governance spans the culture, organization, policy and practices that provide for IT management and control across five key functions [7], [4]. They are:

- Alignment - Provide for the strategic direction of IT and the alignment of IT and the business on services and projects.

- Value Delivery - Confirm that the IT / Business organization designed to drive maximum business value from IT. Oversee the delivery of value by IT to the business, and assess ROI.

- Risk Management - Ascertain that processes are in place to ensure that risks have been adequately managed. Include an assessment of the risk aspects of IT investments.

- Resource Management - Provide high-level direction for sourcing and use of IT resources. Oversee the aggregate funding of IT at the enterprise level. Ensure there are adequate IT capability and infrastructure to support current and expected future business requirements.

- Performance Measurement - Verify strategic compliance, i.e. achievement of strategic IT objectives. Review the measurement of IT performance and the contribution of IT to the business (i.e. delivery of the promised business value).

The key functions outlined above are often referred to as the domains of IT Governance. 


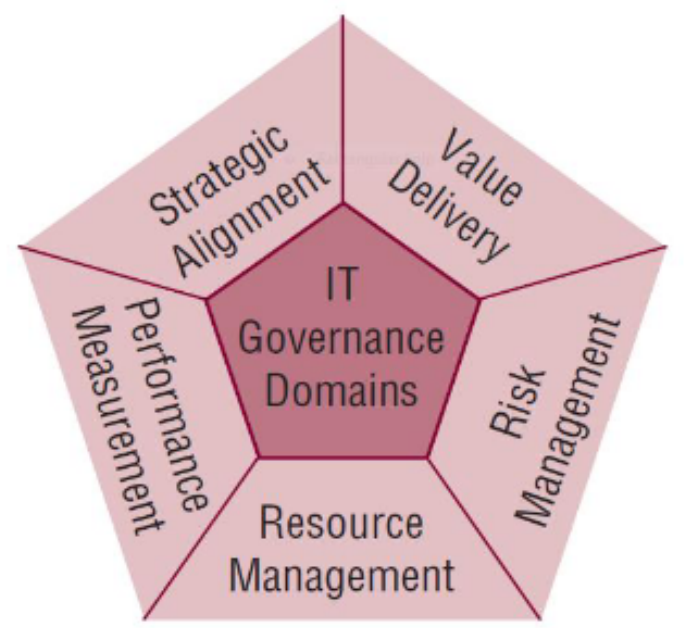

Fig. 1. IT Governance Domains Adapted from Williams (2012) [25]

IT Governance is not a one-time exercise or something achieved by a mandate or by assetof rules. It requires a commitment from the top of the organization to introduce a better way of dealing with the management and control of IT. IT Governance is an ongoing activity that requires a continuous improvement mentality and responsiveness to the fast-changing IT environment. IT Governance can be integrated within a wider Enterprise Governance approach, and support the increasing legal and regulatory requirements of Corporate Governance.

ITG is closely associated with the strategic management of IT. Aligning organizational strategy and use of IT is a key function of ITG. The strategic process for determining the role of IT solutions in organizational anything but linear. Integrating all the components of the strategic process is cyclic. The key elements of this cycle are:

- Strategic Analysis - involves establishing an understanding of the current situation, including aspects of the environment; current technology infrastructure; available resources; expectations; broad objectives; and power bases.

- Strategic Choice - involves the formulation of the strategy itself through understanding various options, evaluating options and making a decision on a suitable strategy.

- Strategy implementation - involves tactical issues such as resource assessment and planning, identifying human resources and systems, contents, determining organizational structure and so forth.

The first two stages of the strategy cycle should ideally result in methods, constructs, and values that facilitate ITG practices in organizations [1], [2].

ITG is also associated with decision-making hierarchies when IT solutions and services are deployed [2] typical hierarchy for IT strategic management could include:

- Mission and Goal - With a high-level focus, what are we planning to achieve with IT solutions and services?

- Strategies - In deploying IT, what alternative pathways are available?

- Policies - How should we be guiding our moves within a selected pathway to deploy IT?

- Decisions - What alternative options for moves (above) should be considered? This level of the hierarchy is associated with determining specific IT projects.

- Action - This is the way we will implement our decision for introducing IT solutions. It involves project implementation and service delivery

Finally, in wrapping up this section, given the nature of the IT industry and rapid changes in technology development, the process of ITG and strategic management of IT needs to be cyclic [1], [2]. That is to say; there is a need to monitor technology advancements and re-evaluate IT directions periodically. 


\section{Current State of ITG Standards}

In addition to the overarching philosophies, ITG practices make use of standards, frameworks, and tools. Firms may approach the governance of IT without making use of specific frameworks and standards on an ad hoc basis. Alternatively, they may adopt standards that have been developed by professional bodies and standard-setting organizations. Some of the most widely used ITG standards are outlined below.

- ITIL-This framework was originally developed during the 1980 s by the United Kingdom government. It is still owned by the UK Government (a department called the OGC). ITIL has become the most widely adopted ITG framework. ITIL covers the organizational structure and skill requirements for an IT organization / area by presenting a comprehensive set of management procedures. These are intended to be an independent supplier and apply to all aspects of IT Infrastructure The IT Infrastructure Library (it's the full name) is fundamentally a collection of eight books, the contents of which are referred to as 'sets.' These 'sets' are sub-divided into what is termed disciplines', each of which defines a specific subject [8].

- Balanced Scorecard -The balanced scorecard method, also known as the BSC, was developed in 1987 by Analog Devices, a mid-sized semiconductor company. However, it wasn't until 1996 when the BSC was widely recognized. The recognition came from an article by Robert S. Kaplan and David Norton, titled 'The balanced scorecard: measures that drive performance'. The wider recognition in 1996 led to wide-scale adoption of the techniques in subsequent years. The balanced scorecard is a framework for measuring organizations' activities concerning organizational vision and its broad strategies. BSC measures a business from four perspectives: financial, customer, business process, and learning and growth.

- COBIT - COBIT was first released in 1996 by the Information Systems Audit and Control Association (ISACA). The second edition of COBIT was launched in 1998. The third edition was introduced in 2000 followed by a fourth edition in recent times. COBIT is a framework for information IT management risks, or more formally, a "framework and supporting toolset that allows managers to bridge the gap between control requirements, technical issues, and business risks" (ref: ISACA).

- ISO 17799 -This framework focuses on information security governance. It has existed in one form or another for over a decade. It was originally published by a government department in the United Kingdom (the 'DTI'). From there it was published as BS7799 by the BSI, and eventually as ISO 17799 by ISO in December 2000. In 2002, an associated standard, BS7799-2, was published. In 2005, ISO 17799 was re-published, to reflect changes in technology. Later in the same year, BS7799-2 became an ISO standard: namely ISO 27001.

- Prince 2 - Prince (the forerunner of Prince2), was originated from a methodology called II and based on Project, Resource, Organization, Management and Planning Techniques -originally published in 1975. In 1979, the framework was adopted by a United Kingdom Government department (CCTA) . CCTA created the first version of Prince and published it in 1989. Following considerable consultation, Prince2 was released in 1996. Prince2 is a process-based approach to project management.

- Six Sigma - The Six Sigma framework was developed at Motorola (the mid-1980s). It was developed by Bob Galvin and a Motorola engineer, Bill Smith. Six Sigma was widely adopted by large manufacturing companies, such as Honeywell and General Electric. Six Sigma is a quality management program. It monitors, measures, and seeks to improve an organization's operational performance-by identifying and correcting procedural errors. Six Sigma defines two methodologies, known as DMAIC (Define, Measure, Analyze, Improve, Control) and DMADV (Define, Measure, Analyze, Design, Verify). DMAIC seeks to improve existing processes. DMADV is used to develop new, customer-focused processes.

- COSO (Committee of Sponsoring Organizations) - COSO defines internal control as a process. The process is affected by a unit's board of directors, management, and other personnel. It is designed to ensure achieving objectives. The objectives are divided into various categories, such as; effectiveness and efficiency of operations, the reliability of financial reporting, and compliance with applicable laws and regulations. Indeed, COSO recommends approaches to be considered by management teams to evaluate, report, and improve control systems [21], [22]. 
- NIST 800-14 - It is related to information security governance. It facilitates establishing a comprehensive IT security program [16].

- ASL (Application Services Library) -ASL is a collection of best practice guidance for managing application development and maintenance. It is a public domain standard for application management. It is different from ITIL but it follows similar philosophies in adhering to standards for managing processes and providing a coherent, and rigorous set of guidance in the public domain [16].

The brief review of some of the standards above indicates that the majority of standards originated in the late 1990s. However, some were fine-tuned and evolved to reflect some of the changes in the sector. The sample studied above does not indicate significant changes in standards within the last decade. At the same time, bot technology and practices in adopting technology have undergone significant changes. Therefore, there is the question of how effective could these standards be if it is likely that they have not been revised to reflect recent changes?

\section{An Introduction to Cloud Services}

Since the establishment of the philosophy, practices, and standards of ITG, the IT industry has undergone significant changes. Most of the changes experienced in the sector originate from the rapid advancement of networking technologies, including mobile networks.

One of the most significant developments in recent times has been advancements in technologies that support the practice of Cloud Computing. The advancements have resulted in increased uptake of Cloud Services resulting in major paradigm shift in the management of applications and infrastructure of IT.

In 1969, Leonard Kleinrock, one of the chief scientists of the original Advanced Research Projects Agency Network (ARPANET) project, said: "As of now, computer networks are still in their infancy, but as they grow up and become sophisticated, we will probably see the spread of 'computer utilities' which, like present electric and telephone utilities, will service individual homes and offices across the country. "This vision of the computing utility based on the service provisioning model anticipates the massive transformation of the entire computing industry in the 21 st century whereby computing services will be readily available on demand, like other utility services available in today's society.

The term "Cloud" originated from a telecommunications term in the 1990s when service providers began using virtual private network (VPN) services for data communication. VPNs maintained the same bandwidth as fixed networks with considerably less cost: these networks supported dynamic routing, which allowed for a balanced utilization of the network and an increase in bandwidth efficiency, and led to the coining of the term "telecom cloud." Cloud computing's premise is very similar in that it provides a virtual computing environment that is dynamically allocated to meet user needs. Cloud computing is defined as "A model for enabling convenient, on-demand network access to a shared pool of configurable computing resources (e.g. networks, servers, storage, applications, and services) that can be rapidly provisioned and released with minimal management effort or service. provider interaction ". The term "Cloud Computing" is a general term for IT solutions and services that involve delivering hosted services over the Internet. Cloud computing encompasses a whole range of services that can be hosted in a variety of approaches. Typical services offered via the Cloud Are:

- Infrastructure-as-a-Service (IaaS) - Delivers computer infrastructure as a utility service, typically in a virtualized environment. Also, it provides normal potential for extensibility and scale.

- Platform-as-a-Service (PaaS) - Delivers a platform or solution stack on a cloud infrastructure. It also sits on a top of the IaaS architecture and integrates with development and middleware capabilities as well as database, messaging and queuing functions.

- Software-as-a-Service (SaaS) - Delivers the application over the Internet or Intranet via a cloud Infrastructure. It is built on the underlying IaaS and PaaS Layer.

Cloud platforms such as Infrastructure as a Service, Platform as a Service and Software as a Service are dynamically built through virtualization with provisioned hardware, software, networks, and datasets. Cloud Computing consists 
of virtual services being delivered through a virtualized environment. Cloud customers can access their data anywhere in the world on demand. For that reason, the Cloud is seenas "a single point of access" to the computing needs of its customers delivering a robust and readily available infrastructure. Alongside providing effective solutions, Cloud Computing also introduces challenges and concerns. Some of these challenges impact on specific domains of ITG (for instance risk management). For instance, Cloud service delivery by companies offering Cloud solutions requires new standards and regulatory requirements. New Zealand Institute of IT Professional (IITP) developed and put in place a set of regulatory requirements known as Cloud Code of Practice (https://cloudcode.nz/).

Adopting cloud solutions in organization demand governance models to ensure a secure cloud computing environment and to comply with all relevant organizational information technology policies. Some governance models have been developed to facilitate the adoption of cloud solutions. Governance of cloud solutions will need to be acknowledged and impacted upon current ITG standards.

\section{Impact of Cloud Solutions on IT Governance Standards}

Cloud computing is a "combination of technologies through which dynamically scalable and often virtualized resources are provided as a service over the Internet. Users need not know, expertise in or control over the infrastructure in the cloud. " [11] Adopting cloud services transforms the role of IT operations management from managing IT operations to managing IT as a service. If previously, the IT managers ran the internal "IT Factory," now, "both enterprises and external service providers have become producers and consumers of services" [11], [12]. The adoption of cloud services has increased significantly. The shift of the paradigm of infrastructure management and the complexity of managing various components of services via the cloud has complexity in the need for implementation of specific aspects of IT governance.

Adoption of cloud services for delivery of some or all of IT services has implications for both IT and business processes. Consequently, fine-tuning IT governance models and practices for adopting and using the cloud is a critical aspect of the adoption of technology. The cloud governance practice is often referred to as Governance of Enterprise IT (GEIT) [11], [12]. The reasons are:

- Managing the increased risk as the result of using cloud technologies (for instance the risk to privacy, security, and compliance).

- Ensure security and continuity of critical business processes - processes that extend beyond a typical data center.

- Managing the communication of organizational objectives - both within the organization and to the third party providers.

- Adopting flexibility, and scalability of services that are modified via adopting cloud services -allowing for increased productivity and reduced costs.

- To communicate clear enterprise objectives internally and to third parties.

- Facilitating the continuity of IT knowledge.

- Managing cloud services regulations.

The cloud presents the opportunity for organization to align IT with broader organizational strategies in a more effective manner. Adopting tools and processes that facilitate the alignment process are a critical component of adopting cloud services. ISACA defines governance as "the set of responsibilities and practices exercised by the board and executive management with the goal of providing strategic direction, ensuring that objectives are achieved and ascertaining that risks are managed." ISACA defines five outcomes of good governance. However, GEIT is primarily concerned with two outcomes:

- IT value delivery to the business

- The management of IT-related risks.

The two outcomes above are enabled by the other three outcomes identified by ISACA: 
- Strategic alignment of IT to the business

- The availability and management of adequate resources

- The measurement of performance to monitor progress toward the desired goals

ISACA has developed several GEIT frameworks to assist IT executives and managers with integrating and aligning the adoption of cloud services into the broader IT governance practices. Some of these tools were discussed earlier under the broader IT governance standards in section III. GEIT tools and frameworks include:

- COBIT - The comprehensive GEIT framework that addresses every aspect of IT and integrates all of the main global IT standards

- Val IT - The GEIT framework that focuses on value delivery and ensures that IT-enabled investments are managed through their full economic life cycle

- IT Risk - A set of guiding principles and the first framework to help enterprises identify, govern and effectively manage IT risk

- BMIS - A holistic model for managing information security that takes a business-oriented approach. While these tools have not been designed specifically for cloud environments, the principles are applicable.

In conclusion, the adoption of cloud services significantly increases the importance of adopting effective It governance methods and processes.

\section{Conclusions}

Today, investment in IT is possibly the largest component of a typical budget in many organizations. It is estimated that the global IT expenditure in 2007 was $6 \%$ of the total GDB, and it is likely to have grown to $10 \%$ of global GDP in 2012 and beyond. As investment in ICTs continues to grow, there is an increasing expectation for accountability and that this investment is made wisely to maximizer returns. Effective decision making is a key factor in ensuring the highest possible returns on ICT investments. More specifically, decisions on the direction of the use of IT in organizations must be aligned with strategies driving the business. In many organizations, ITG guides and facilitates IT initiatives and investments.

ITG practices are comprised of concepts, philosophies of governance, organizational culture, standards, frameworks, and tools. This study looked at the history of concepts and standards.

The review of a range of philosophies, definitions and concepts highlighted that they were mostly presented in the late 1990s and early to mid-2000s. The period when these concepts were presented seems long before major technology transformation took place in the IT sector within the last decade. Similarly, the review of a sample of most widely known standards revealed that the majority of standards originated in the late 1990s. Some were fine-tuned and evolved to reflect some of the changes in the sector in recent times. The sample did not, however, indicate significant changes in standards within the last decade.

At the same time, within the last decade, technology and practices in adopting technology have undergone significant changes. The paper outlined Cold Services as a significant change in the IT sector in recent times. Given discussions in the paper, there seems to be a need to investigate the effectiveness of current ITG practices, standards, and frameworks. A broad review of some of the governance practices after the introduction of cloud services reveals that there have been implications for IT governance standards and models. More specifically, some of the frameworks have been fine-tuned (to some extent) to allow the adaptation of this new service philosophy within organizations more effectively.

\section{References}

[1] Asgarkhani, M. (2011). The Challenge of ICT Governance in the Information Age. Proceedings of the 2nd International Conference on Business and Economic Research, (pp. 2403-2412).

[2] Asgarkhani, M. (2013). Asgarkhani, M. (2013). Corporate IT Governance: A Tool for IT Best Practice. Proceedings of the International Conference on Management, Leadership and Governance. 1: 1-8. 978-1-909507-00-5. 
[3] Brown, C., and Magill, S. (1994) Alignment of the IS Functions with the Enterprise: Toward a Model of Antecedents. Management Information Systems Quarterly, 18, 4 (1994), 371-404.

[4] Cristian, H. (2010), Seven habits effective IT governance, Available HYPERLINK "http://www.emeraldgrouppublishing.com/learning/management_thinking/articles/pdf/hagen_it.pdf?PHPSESSID=g6u235a0 sb00hc6vj5mvjf2fublishing .com / learning / management_thinking / articles / pdf / hagen_it.pdf? PHPSESSID = g6u235a0sb00hc6vj5mvjf2f54, Emerald group publishing 2010

[5] IT Governance Institute. (2007). COBIT 4.1. Illinois: IT Governance Institute.

[6] IT Governance Institute. (2012, April 5). About IT governance. Retrieved from IT Governance Institute: http://www.itgi.org/template_ITGIa166.html?Section=About_IT_Governance1\&Template=/ContentManagement/HTMLDis play.cfm\&ContentID $=19657$

[7] IT Governance Institute. Board Briefing on IT Governance, 2nd edition, IT Governance Institute, 2004

[8] IT Infrastructure Library. (2007). An Introductory Overview of ITL. The UK Chapter of the itSMF.

[9] Jaimin, N., \& Shah, U. a. (2012, April). Cloud Computing for Business. Retrieved from citeseerx.ist.psu.edu: $\mathrm{http} / / /$ citeseerx.ist.psu.edu/viewdoc/download?doi=10.1.1.417.444\&rep=rep1\&type=pdf

[10]Kai, H., \& Deyl, L. (2015, 08 18). Cloud Computing with Secure Resources and Data Coloring. Retrieved from citeseerx.ist.psu.edu:

HYPERLINK "http://citeseerx.ist.psu.edu/viewdoc/download?doi=10.1.1.231.6761\&rep=rep1\&type=pdf" http: //citeseerx.ist.psu. edu / viewdoc / download? doi $=10.1 .1 .231 .6761 \&$ rep $=$ rep1 \& type $=$ pdf

[11] Kaufman, L. (2009, August). Data Security in the World of Cloud Computing. Retrieved from file: /// C: /Users/Andreea/Downloads/NDU-2.pdf

[12] Kodama, M. (2002). Strategic Partnership with Innovative Customers: A Japanese Case Study. Journal of Information Systems Management, 31-52.

[13]Luftman, J. (1996) Competing in the Information Age. Oxford, Oxford University Press, 1996.

[14] Mandala, V., Bhaskar, R., \& Marepalli, C. (2012, January). Cloud Computing Organizational Benefits A Managerial Concern. $\quad$ Retrieved from ww.bth.se: http://www.bth.se/fou/cuppsats.nsf/all/ad7847243c12eb23c1257aba004e8a24/\$file/BTH2012BhaskarReddy.pdf

[15] Meijer, M. (2003). Application Service Library (ASL) and CMM. bITa Monitor - The Journal of IT Alignment and Business IT Alignment, Vol. 1 (1), March, pp. 21-26.

[16] National Institute of Standards and Technology (NIST), An Introduction to Computer Security: The NIST Handbook, Special Publication 800-12, USA, 1996

[17] Prasad, A., Green, P., \& Heales, J. (2008). TOWARDSA DEEPER UNDERSTANDING OF INFORMATION TECHNOLOGY. Brisbane: The University of Queensland.

[18] Rajkumar, B., Chee Shin, Y., \& Srikumar, V. (n.d). Market-Oriented Cloud Computing: Vision, Hype, and Reality for Delivering IT Services as Computing Utilities. Retrieved from arxiv.org: HYPERLINK "http://arxiv.org/ftp/arxiv/papers/0808/0808.3558.pdf" http://arxiv.org/ftp/arxiv/papers/0808/0808.3558.pdf

[19] Sambamurthy, V., and Zmud, R. (1999) Arrangements for information technology governance: a theory of multiple contingencies. Management Information Systems Quarterly, 23, 2 (1999), 261-290.

[20] Schwarz, A. and Hirschheim, R. (2003) An extended platform logic perspective of IT governance: managing perceptions and activities of IT. The Journal of Strategic Information Systems, 12, 2 (July 2003), 129-166.

[21] Van Grembergen, W. (2004) Strategies for Information Technology Governance, Idea Group Publishing, 2004.

[22] Van Grembergen W. (2002) Introduction to the mini track: IT Governance and its mechanisms. Proceedings of the 35th Hawaii International Conference on System Science (HICSS), IEEE, 2002.

[23] Weill, P. (2004). Don't just lead, govern: How top performing firms govern IT. MIS Quarterly Executive, 3 (1), 1-14.

[24] Weill, P. and Ross, J. (2004), IT governance, Boston, Massachusetts, Harvard Business School Press, 2004

[25] Williams, P. A. (2012, April 2). Optimizing Value Creation From IT Investments. Retrieved from Governance Institute: http://www.isaca.org/Knowledge-Center/Research/Documents/Outsourcing.pdf 